\title{
A THEORETICAL FOUNDATION FOR DEVELOPING A PRESCRIPTIVE METHOD FOR THE CO-DESIGN OF CIRCULAR ECONOMY VALUE CHAINS
}

\author{
Blomsma, Fenna; Pigosso, Daniela C.; McAloone, Tim C. \\ Technical University of Denmark
}

\begin{abstract}
In order to operate in line with the circular economy (CE) concept, companies and other stakeholders need to work together to enable the circulation and cascading of resources. Although the need for proactive stakeholder management is a common theme in recent work on CE, little work has been dedicated to creating prescriptive methods for the co-design of $\mathrm{CE}$ value chains (CEVCs) focusing on selecting strategic partners, when to engage them and in what capacity. Following calls to connect the emerging CE literature with literature from existing bodies of knowledge, this paper explores the theoretical foundations of a CEVCs co-design method. Specifically, this paper explores resource-base view (RBV); resource dependency theory (RDT); and actor-network theory (ANT), and synthesises an outline for the co-design process of CEVCs. Reflections on the process link it to the extant co-design literature and explain how the process can be used for method and tool development.
\end{abstract}

Keywords: Collaborative design, Collaboration, Circular economy, Organizational processes

\section{Contact:}

Blomsma, Fenna

Technical University of Denmark

MEK

Denmark

fblo@dtu.dk 


\section{INTRODUCTION}

The Circular Economy (CE) concept proposes to move away from consumption and production systems based on linear take-make-use-dispose practices. Instead, CE advocates the application of circular strategies in line with the creation of societal, environmental and economic value, whilst at the same time reducing, avoiding and negating value loss and destruction (EMF 2013, Blomsma and Brennan 2017). Circular strategies are strategies aimed at reducing or removing structural waste across all stages of resource use. This can be done through 1) avoiding excess or harmful use of resources (e.g. efficiency, bio-compatibility), 2) addressing premature end-of-life of materials (e.g. recycling, composting), 3) ensuring subsequent use of materials (e.g. substance cascading, downcycling), 4) combating premature end-of-use of products (repair, refurbish, etc), 5) promoting the use of excess product capacity (sharing, co-use), or 6) a combination of these (Blomsma and Tennant, in review).

Due to the specialised role of stakeholders involved in industrial systems, few are likely to be able to operate in a circular manner entirely autonomously (Kraaijenhagen et al., 2016). Instead, companies and other stakeholders need to work together to enable the circulation and cascading of resources. Currently, however, there still exists a "circularity gap:" a lack of connections for enabling value chains (VCs) and networks (Schmid and Ritzrau, 2018).

So far, the CE literature has primarily focused on the practical and technical levels of physical flows in industrial systems (Korhonen et al., 2018). Where the focus has been on organisational aspects, this is often with particular emphasis on conceptualising and designing circular business models, acknowledging but not providing detail on the role of the $\mathrm{VC}$ in the process of value creation, value capture or value delivery (Geissdoerfer et al., 2018; Boons and Bocken, 2018). A second body of work has attempted to better understand the development of CEVCs, but this is so far characterised by descriptive case studies, understanding factors regarding product design and manufacturing, demand and consumption, end-of-life recovery and cycling of individual products, components or materials (e.g. Franco, 2017).

Although the need for proactive stakeholder management is a common theme in recent work on CE, little work has so far been dedicated to creating prescriptive methods for the co-design of CEVCs focusing on how to select strategic partners, when to engage them and in what capacity. Within the literature on co-creation and co-design, likewise, limited guidance exists with regards to these topics (Guertler et al., 2016). At the same time, calls are voiced to better connect the CE literature to other bodies of knowledge (Lahti et al., 2018).

For these reasons, this paper explores how theory from organisational and science and technology studies can inform the creation of a prescriptive approach for the co-design of CEVCs, and what CE specific circumstances need to be considered. The following bodies of work were selected for the exploration in this paper, as they respectively highlight elements that are relevant to how organisations deal with resources and facilitate a processual and networked approach to change processes: resource base view (RBV); resource dependency theory (RDT); and actor-network theory (ANT). The next section introduces the theories and explores what guidance they provide the process for co-design of CEVCs. Subsequently, this is synthesised in a proposed outline for the codesign process of CEVCs, it is reflected upon in light of the extant co-design literature, and it is explained how this can be used to select and adapt existing tools as well as design new ones.

\section{EXPLORING THEORIES INFORMING CEVC DESIGN PROCESSES}

As a starting point, in line with Lathi et al. (2018), we draw from well-established work within organisation science by contingency and structural theorists (Miller and Mintzberg, 1983) and define organisations as bundles of resources (Snow et al., 2006). Different conceptualisations of resources and resource groupings exist: see Galbraith (1977), Peters and Waterman (1982), and Miles and Snow (1978). From a CE perspective, it is important to consider those resources that are to be circulated, or: circular material resources (CMRs) (materials or particles, and modules or parts, and finished goods or products) (Blomsma and Tennant, in review) and other material resources (e.g. equipment, facilities, infrastructure, etc). Moreover, organisational competencies, capabilities and resources that create potential for and enable the circulation or cascading of material resources 
are necessary. These include but are not limited to: business processes such as design, sourcing, manufacturing, product operation and through life support, logistical capabilities, but also knowledge and cultural resources such as leadership. The total set of a businesses' material and organisational resources and their structure can be designated as a company's resource configuration.

Linked to this conceptualisation of organisations is the resource-base view (RBV). According to $\mathrm{RBV}$, a company deploys its resource configuration to create alignment or fit with its environment. This fit is its source of value creation. Applying RBV in the context of CE focuses the attention on how resource configurations can be created that enable the circulation of CMRs, whilst simultaneously considering how CMRs contribute to value creation.

Apart from the resources a company directly controls, the resources a company has access to through its value network also play a vital role in a company's success. This part of managing resources is covered by resource dependency theory (RDT), and emerging work has shown it to be key for CEVCs also (Franco, 2017). Drawing on RDT can thus provide insight into how effective cycling or cascading of CMRs can be achieved by considering how resources can be accessed or obtained from the environment and how to manage resulting dependencies.

The relationship between RBT and RDT can be understood in different ways, depending on the scope of the analysis. One can adopt a company centric view (Fig. 1a), focus on dyadic relationships (Fig. 1b), or be network oriented (Fig. 1c). As this research is concerned with CEVCs, we adopt a networked perspective (Allee, 2000), where one company's output becomes another company's input. In such cases the RBV of one organisation is intertwined with another's RDT perspective. Each company in a CEVC wields the resources under its control to create value and to maintain and improve its position, whilst at the same time relying on other companies to provide complementary resources so that the chain can function as a whole. This means that in CEVCs value creation and capture capabilities are inextricably intertwined with the creation of dependencies. As such, to understand the dynamics in CEVCs it is important to consider the interaction between CMRs and the resource configuration of the network as a whole.

Based on this, we advance the following definition of CEVCs: CEVCs are a composite of the resource configurations of the different companies participating in a $\mathrm{VC}$, that through

their synergistic deployment allow for cycling and/ or cascading of CMRs. This is similar to the 'extended enterprise' concept, which involves the coordination across company boundaries, allowing a group of companies to combine their respective capabilities (Miles and Snow, 1994).
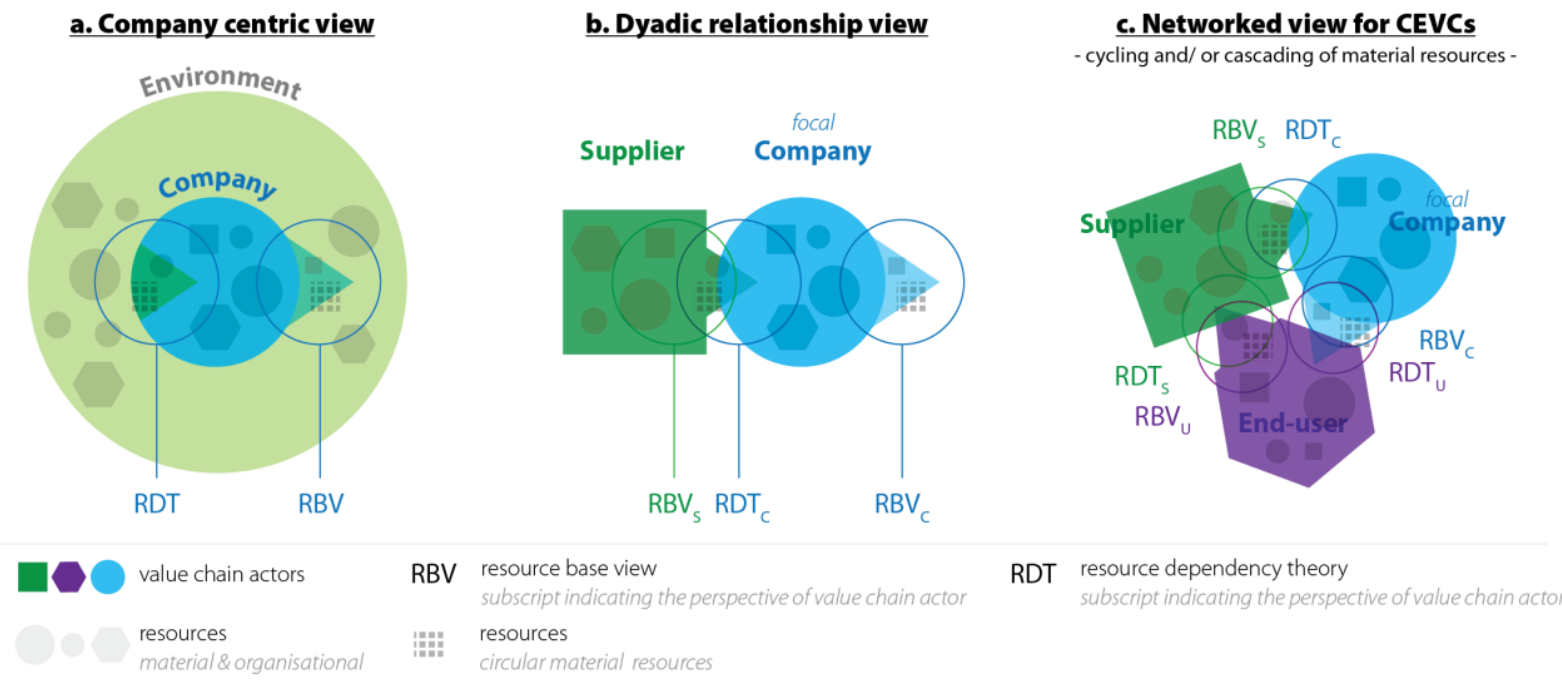

Figure 1. a-c Different perspectives on RBT and RDT 
The above has shown that RBV and RDT are key theories to explore in the context of designing CEVCs. Next, we discuss RBV and RDT in more detail, exploring how they inform the creation of a prescriptive method for the co-design of CEVCs. This is followed by an examination of what RBV and RDT overlook, and how this gap can be addressed.

\subsection{Resource-base view (RBV)}

The resource-base view, also known as resource-base theory, emerged as a reaction to the then dominant view in organisation science that industry structure is the primary determinant of firm performance (Kraaijenbrink et al., 2010). RBV poses the complementary view that the alignment of companies' internal resource configurations with their environment provides them with their value creation capabilities. To do this a company must acquire and control valuable, rare, inimitable, and non-substitutable resources, competences and capabilities, and have the organization in place to suitably absorb and deploy them (Barney, 2002).

High-performing organisations, according to RBV, are organisations that maximise value creation from their resource configurations. These tend to be organisations that are able to adapt their resource configurations to exhibit a particularly high degree of alignment between the offering resulting from the exploitation of the resource configuration, and what is wanted or needed in the organisation's environment (Miles and Snow, 1984). Moreover, to continue to perform well, a company needs to deal with changes in its environment, and thus - often routinely - modify the resource configuration.

RBV also brings into focus the role of people in shaping companies. It considers that the deployment of a resource configuration is performed by boundedly rational managers that are competing to outperform each other with regards to 1) estimating the future value of a resource, and 2) the creation of isolating mechanisms to perpetuate their respective advantage "beyond others' efforts to duplicate or eliminate it" (Kraaijenbrink et al., 2010), in environments where information is asymmetrically distributed. Company performance, therefore, depends on its access to information, and the sensemaking capacity of its managers.

\subsubsection{What the RBV brings into focus for the co-design process for CEVCs}

The RBV helps in understanding transitioning to circular systems in the following ways. For one, it provides a starting point for CEVC development. For a company aspiring to implement circular solutions, the RBV tells us that it is necessary to start with an understanding of what opportunities for value creation and capture can be created through addressing structural waste. Understanding this clarifies: 1) the possible CMRs to be circularised or cascaded, and the 2) opportunities this represents to the company.

Second, it needs to be understood what internal resources and capabilities the company has or can make available for capturing the opportunity. It is furthermore important to consider internal sources of inertia in changing the resource portfolio as existing resources and capabilities can limit the directions for new resource investments (Lahti et al., 2018) resulting in path dependency for change processes. This has also been shown to be a source of tension in the area of CE (Hopkinson et al., 2018). Based on this, some circular strategies may appear more feasible than others, and some opportunities may appear larger than others. This further details the opportunity that the application of circular strategies represents for the company.

However, as was shown, this company view needs to be complemented by a network perspective if circular strategies are to be implemented. Therefore, we turn to RDT to include the perspective of other stakeholders in the process for CEVC design.

\subsection{Resource-dependency theory (RDT)}

Resource dependency (also: dependence) theory poses that companies are dependent on other organisations in their environment for acquisition, access and maintenance of strategically critical resources for their continued existence (Pfeffer and Salancik, 2003). RDT suggests that companies should adjust their structure and behaviour in order to reduce both uncertainty in and dependency on their environment through the application of control mechanisms (e.g. Hillman et al., 2009) - e.g. 
collaborations, coalitions and partnerships, which can either be trust based or underpinned by legal agreements. Such mechanisms should reduce overall uncertainty (e.g. Hillman et al., 2009), by 1) minimising (the impact of) a company's dependence on other organizations and 2) maximizing the dependence of other organisations on the company. Furthermore, companies may also negotiate with their external environment to secure access to resources. As such, companies not only have the capacity to adapt and change themselves, but also to shape their environment to suit the company's needs.

The application and design of control mechanisms is subject to three main factors (Pfeffer and Salancik, 2003). First, the activities of a company and its performance are evaluated by its environment: stakeholders outside the company determine the value of an activity. As such, there is a need to reduce the uncertainty that is associated with such external assessment, or the impact this may have. Second is the dynamic of interdependencies: coalitions in value networks change continuously, and with it the extant power structures (Emerson, 1962). Therefore, there is a need to review power structures on an on-going basis if $\mathrm{VC}$ performance is to be maintained and improved. Third, a company is bound by the structure within which it is embedded: external mechanisms exist that control what a company can and cannot do. These consist of legislation, markets, resource availability and geographical/ cultural norms. Together these factors determine the degree of uncertainty that exists, to which extent control mechanisms are needed (Pfeffer and Salancik, 2003) and what form they should take: e.g. enforcement of power, or trust-based mechanisms (Schnittfeld and Busch, 2018).

\subsubsection{What RDT brings into focus for the co-design process for CEVCs}

The presence of external assessment of value points to the need for involving stakeholders in processes of co-design. Through this, information can be shared and perceptions aligned. However, conflicting stakeholder expectations may exist, so care must be taken that the right stakeholders are involved at the right stages of the process. Specifically, stakeholders in CEVCs may not be the same as those in linear VCs (Kraaijenhagen et al., 2016). One way that appropriate stakeholders for codesign can be found is through identifying and understanding their interests and linking this to the creation of shared value (Porter and Kramer, 2011). This means that a stakeholder's RBV or RDT should be considered as part of the focal company's RDT or RBV, depending on whether the stakeholder is located up- or downstream.

In addition to this, RDT points to be need for understanding how the stakeholder's knowledge and capabilities are complementary or synergistic with that of the focal company. Specifically: are the required knowledge and capabilities present for the circulation or cascading of CMRs, or do gaps exist? If gaps exist, stakeholders outside the current $\mathrm{VC}$ may need to be invited or created. For this reason, a CEVC co-design process has to allow for the discovery of new stakeholders. Moreover, whenever new stakeholders are invited the earlier identified possibilities for shared value creation through CE need to be verified as well as further developed, now that new information is available. This means that iterations of a CEVC design may be required before the full set of relevant stakeholders is identified and the possibilities for shared value creation are clear and sufficiently developed.

RDT furthermore articulates that it is necessary to establish effective control mechanisms. This is not necessarily straightforward: it has been shown that organisational interdependence leads to behavioural and outcome uncertainties regarding the actions of interdependent organisations (Cai and Yang, 2008), due to (perceptions of) behavioural uncertainty and threats. In CEVCs, however, resource productivity can be taken as a starting point for the systemic alignment of interests and incentives. This means that mechanisms should be sought that align the interests of all participating stakeholders with resource productivity.

\subsection{Complementary use of RBV and RDT and remaining critique}

The above has shown that RBV and RDT can be drawn on to identify a starting point as well as points to subsequent steps for the development of CEVCs, incorporating both the perspective of a focal company and other (potential) stakeholders. This is in line with earlier work that has shown that RBV and RDT can be used in a complementary manner through allowing for the examination 
of both the internal and external approach to resource management (e.g. Brennan and Tennant, 2018; Fraczkiewicz-Wronka and Szymaniec, 2012). However, RBV and RDT are not free of critique, some of which is relevant for CEVCs.

First, RBV has been critiqued for its ambiguous and self-referential definitions of value (Priem and Butler, 2001). That is: RBV does not clarify what, exactly, is meant by 'value.' Second, Barney (2002) points out that RBV is valid as long as the 'rules of the game' in an industry remain relatively stable: it does not serve well in environments where the value of resources can change due to the influence of new technologies, new markets and new practices. However, CE frequently involves reframing structural waste as opportunities to create value, which in turn may involve changing the 'rules of the game' - such as through rethinking and reconfiguring the value generation architecture or striving for radical decoupling of resource use from value creation, such as through a change in business models (e.g. access-over-ownership models) and a change in paradigm (e.g. digitalisation).

Related to these points is a third point of critique. The CE view may differ from the classic RBV with regards to resources needing to be unique and inimitable. Recent work on green and sustainable VCs has shown that companies pursuing value creation in line with sustainable development aim for the creation of replicable capabilities and shared resources (Glavas and Mish, 2015). This provides the chain or network as a whole with an enhanced potential for value creation. As such, in the CE context CMRs are to be circulated or cascaded between actors through multiple value creation cycles enabled by complementary organisational resources. This implies that a shift in perception is necessary, that not only includes the generation of shared value, but also shared ownership and risk sharing with regards to creating and maintaining CMRs and organisational resources.

A fourth source of critique on both RBV and RDT is that viewing companies as bundles of resources is too simplistic a view of reality. Although both perspectives acknowledge the role of managers' bounded rationality and perceptions of different valuations by stakeholders, they do not account for such radically different perceptions as to what constitutes a 'resource' in the first place, for instance. Such differences have been shown to complicate change processes towards CEVCs, leading different actors to set different priorities, emphasise different success factors and set different scopes for CE (Hagelüken, 2014; Lapko et al., 2018).

Kraaijenbrink et al. (2010) point out directions for the development of RBV that address this critique. The authors argue that it is necessary to adopt a perspective that makes explicit the process for how value is conceptualised and its meaning negotiated, from imaginings to enactment in the form of explorative action. Snowden and Boone (2007) summarise this approach to engaging with complex systems as a 'to probe, sense and respond'-approach. This furthermore requires expanding the notion of who is considered a 'stakeholder,' since in dynamic environments the locus of value creation may lie within or outside companies (for example: regulators and standard bodies shaping relevant infrastructure). This involves considering the use of rhetoric, power, and negotiation (Coff, 1999).

Related to this is the bi-directional interaction between mental models and physical reality: a given physical reality shapes mental models and mental models allow for interpreting that same physical reality (Weick, 1995). This is particularly salient in the context of resources: resources shape value perceptions and vice versa (Foss et al., 2008; Mahoney, 1995).

To overcome this critique and develop a co-design approach that is suitable to deal with the complexities of developing CEVCs a perspective is required that 1) focuses on the negotiation of meaning in relation to value, the 'rules of the game,' and ownership and risk. Moreover, this perspective needs to 2) allow for emergence, both with regards to who is involved in the change effort as well as in the understanding of what is being created. Lastly, 3) the perspective needs to accommodate for a role for both physical and non-physical resources. For these reasons, we turn to actor network theory (ANT), as it incorporates these aspects.

\subsection{Actor-network theory (ANT)}

Actor-network theory was first developed by philosopher Bruno Latour and colleagues Michel Callon and John Law. Similar to Weickian sensemaking (Weick, 1995), ANT is best understood as a perspective and method, rather than a theory with explanatory or predictive capacity. ANT revolves 
around the idea that networks of actors 'hold in place' structures in society (Latour, 2005). That is: ANT acknowledges the presence of structure, but poses that this structure is precarious, as it requires constant enactment, performance and confirmation. Without this constant recreation, these structures would quickly dissolve.

ANT aims to understand change and inertia by making actor networks visible. This involves drawing boundaries around structures, examining what actors are inside the boundary, exposing what interpretive frames the actors within this boundary hold and how these are coherently integrated into narratives. Rather than setting static boundaries, however, ANT works 'with' boundaries and adjusts them as required by what is uncovered. Adopting the perspective of ANT means focusing on what is punctualised, what assumptions are held, how issues are problematised, and how action is generated through enactment, enrolment and mobilisation processes. ANT considers how such processes constrain solution spaces, and where and why (selective) translation takes place. It pays particular attention to commonalities, but also to differences in framing, such as tensions and slippages.

When used to inform and guide change processes, ANT can aid in articulating frames, such that active reframing can take place. In this sense, innovation is about changing and/or bridging frames. ANT helpfully distinguishes between different roles actors can assume in such processes: intermediaries (their inputs and outputs are the same), mediators (multiply or reduce differences), and those actors that are acted 'with'. This allows for understanding the dynamics between actors in networks. Importantly, ANT allows for actors to be human or physical resources, who are bound together in a web of reciprocal influence. It is by understanding this influence on each other over time that allows for understanding emergence.

ANT's sensitivity to the negotiation of meaning, its incorporation of emergence, and its attribution of an active role to both people and physical resources, make it a means for addressing the above discussed critique on RBV and RDT. This is in line with previous work that has used (aspects of) ANT for understanding CE and resource flows more broadly: several authors have shown the importance of perceptions, coalition forming, and emergence (Boons and Howard-Grenville, 2009; Baumann, 2012; Nilsson-Lindén et al., 2018).

\section{SYNTHESIS \& DISCUSSION: CEVC CODESIGN FOUNDATIONS}

Synthesising the insights gained from RBV, RDT and ANT results in the process as depicted in Figure 2. It consists of three broad phases. The company phase aims to clarify the CE opportunity from the perspective of a focal company. The shared value phase expands on this by seeking opportunities for shared value creation by considering the dynamics on three different levels that could aid or hinder circulating CMRs. First is the network level. Here, it is important to understand the broader system a VC is embedded in. This may involve societal trends, such as changing consumer preferences, but also technological developments. Next, the dynamics on the VC level is to be examined. Here, the focus is on the dynamics of the chain as a whole and the characteristics that help or hinder the transition to a CEVC. Think of the presence of particularly powerful actors or the degree to which information is freely shared between actors. The final level is that of the dyad: the traditional supplier- company, or company-customer relationship. Here, the focus is on how specific relationships shape the flow of CMRs. These steps allow for zooming in on the key strategic partners. In the third phase, alignment of interests, the CEVC configuration is further detailed. Here, the focus is on how actor interests can be aligned with resource productivity, as well as with each other. Think of contracting, revenue and reward mechanisms, etc. Throughout this process, as ANT has shown, it is necessary to be aware of the frames applied, and where boundaries need to be redrawn and active reframing needs to take place. Overall, the process is likely to be iterative to account for new learnings and understandings.

The process outlined in Figure 2 exhibits similarities with the process for co-design described in McAloone et al. (2010), where first the focal company perspective is explored, before involving other stakeholders. Furthermore, similar to Park et al. (2016), the proposed process focuses on how to create a competitive advantage through a collaborative approach. However, this current paper contributes to filling the knowledge gap of applying these principles in the context of CE value 
chains and identifying what $\mathrm{CE}$ specific circumstances need to be considered in such processes, through linking the co-design and CE literature with organisational and science and technology studies.

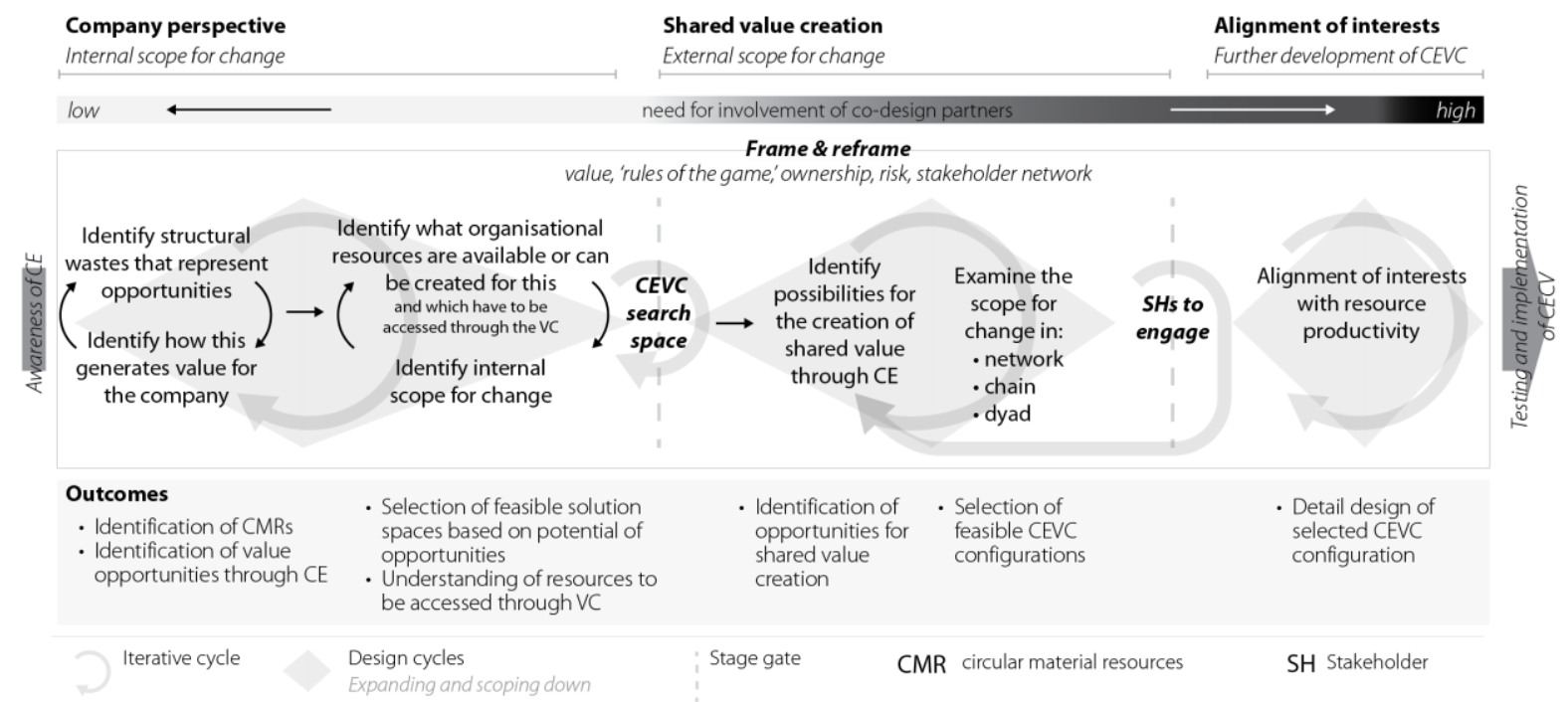

Figure 2. Foundations for a prescriptive approach to the co-design of CEVCs.

The process model in Figure 2 can be used to review the multitude of methods and tools for VC design and select those that are particularly suitable for the development of CEVCs, place them in a coherent narrative, and - if needed - adapt them as to suit the particularities of CEVC design. In addition to this, it can be used to find gaps in the current landscape of methods and tools and create new tools to fit the specific purpose of that particular step in the CEVC design process. As such, this paper provides a theoretical foundation for developing a prescriptive method for the co-design of CEVCs.

\section{REFERENCES}

Allee, V. (2000), "Reconfiguring the value network", Journal of Business Strategy, Vol. 21 No. 4, pp. 36-39. Barney, J.B. (2002), Gaining and Sustaining Competitive Advantage, Prentice Hall, Upper Saddle River, NJ.

Baumann, H. (2012), "Using the life cycle approach for structuring organizational studies of product chains", In: 18th Greening of Industry Network Conference. Linköping.

Blomsma, F. and Brennan, G. (2017), "The emergence of circular economy: A new framing around prolonging resource productivity", Journal of Industrial Ecology, Vol. 21 No. 3, pp. 603-614.

Blomsma, F. et al. "Developing a circular strategies framework for manufacturing companies to support circular economy oriented innovation", in review.

Blomsma, F. and Tennant, M. "Circular economy: preserving particles or products?", Introducing the Resource States Framework. in review.

Boons, F. and Howard-Grenville, J. (2009), The Social Embeddedness of Industrial Ecology, Edward Elgar Publishing Ltd, Cheltenham, UK.

Boons, F. and Bocken, N. (2018), "Towards a sharing economy - Innovating ecologies of business models", Technological Forecasting and Social Change, Vol. 137, pp. 40-52.

Brennan, G. and Tennant, M. (2018), "Sustainable value and trade-offs: Exploring situational logics and power relations in a UK brewery's malt supply network business model", Business Strategy and the Environment, Vol. 27 No. 5, pp. 621-630.

Cai, S. and Yang, Z. (2008), "Development of cooperative norms in the buyer-supplier relationship: the Chinese experience", The Journal of Supply Chain Management, Vol. 44 No. 1, pp. 55-70.

Emerson, R.M. (1962), "Power-dependence relations", American Sociological Review, Vol. 27 No. 1, p. 31-41.

EMF (Ellen MacArthur Foundation) (2013), Towards the Circular Economy: Economic and Business Rationale for an Accelerated Transition, Ellen MacArthur Foundation publications, Isle of Wight. 
Frączkiewicz-Wronka, A. and Szymaniec, K. (2012), "Resource based view and resource dependence theory in decision making process of public organisation - research findings", Management, Vol. 16 No. 2, pp. 16-29.

Franco, M.A. (2017), “Circular economy at the micro level: A dynamic view of incumbents' struggles and challenges in the textile industry”, Journal of Cleaner Production, Vol. 168, pp. 833-845.

Galbraith, J.R. (1977), Organization Design, Addison-Wesley Pub. Co., Reading, MA.

Geissdoerfer, M. et al. (2018), "Business models and supply chains for the circular economy", Journal of Cleaner Production, Vol. 190, pp. 712-721.

Glavas, A. and Mish, J. (2015), "Resources and capabilities of triple bottom line firms: Going over old or breaking new ground?", Journal of Business Ethics, Vol. 127 No. 3, pp. 623-642.

Guertler, M.R., Becerril, L. and Lindemann, U. (2016), "How to identify suitable collaboration strategies for open innovation?", In: Proceedings of International Design Conference, DESIGN.

Hagelüken, C. and Meskers, C.E.M. "Complex Life Cycles of Precious and Special Metals”, Strüngmann Forum Report. E.d. Graedel, T.E. and van der Voet, E. MIT Press., pp. 163-197.

Hillman, A.J., Withers, M.C. and Collins, B.J. (2009), "Resource dependence theory: A review", Journal of Management, Vol. 35 No. 6, pp. 1404-1427.

Hopkinson, P. et al. (2018), "Managing a complex global circular economy business model: Opportunities and challenges", California Management Review, Vol. 60 No. 3, pp. 71-94.

Korhonen, J. et al. (2018), "Circular economy as an essentially contested concept", Journal of Cleaner Production, Vol. 175, pp. 544-552.

Kraaijenbrink, J., Spender, J.-C. and Groen, A.J. (2010), “The Resource-Based View: A Review and Assessment of Its Critiques”, Journal of Management, Vol. 36 No. 1, pp. 349-372.

Kraaijenhagen, C., van Oppen, C. and Bocken, N. (2016), Circular Business - Collaborate and Circulate, Bernasco, C. and Goodchild-van Hilten, L. eds., Circular Collaboration.

Lahti, T., Wincent, J. and Parida, V. (2018), "A definition and theoretical review of the circular economy, value creation, and sustainable business models: where are we now and where should research move in the future?", Sustainability, Vol. 10 No. 8, p. 2799.

Lapko, Y. et al. (2018), "In pursuit of closed-loop supply chains for critical materials: An exploratory study in the green energy sector", Journal of Industrial Ecology.

Latour, B. (2005), Reassembling the Social: An Introduction to Actor-Network-Theory Author(s), Oxford University Press, Oxford, UK.

Mcaloone, T.C. et al. (2010), "Eco-Innovation in the Value Chain”, In: International Design Conference Design 2010 Dubrovnik - Croatia, May 17 - 20, 2010. eco-innovation.

Miles, R. and Snow, C. (1978), Organizational Strategy, Structure, and Process, McGraw-Hill, New York.

Miles, R. and Snow, C. (1994), Fit, Failure, and the Hall of Fame, Free Press, New York.

Miller, D. and Mintzberg, H. (1983), "The Case for Configuration”, In: Morgan, G., ed. Beyond Method: Strategies for Social Research. Sage, Newbury Park, CA, pp. 51-73.

Nilsson-Lindén, H. et al. (2018), "Organizing life cycle management in practice: challenges of a multinational manufacturing corporation”, The International Journal of Life Cycle Assessment, Vol. 23 No. 7, pp. 1368-1382.

Park, J.-E., Choi, Y. and Holt, C. (2016), “Collaborative Design Management”, In: International Design Conference - Design 2016. Dubrovnik - Croatia. May 16-19.

Peters, T.J. and Waterman, R.H. (1982), In Search of Excellence: Lessons from America's Best-Run Companies, Harper \& Row, New York.

Pfeffer, J. and Salancik, G. The External Control of Organizations: a Resource Dependence Perspective, Stanford University Press, Stanford, CA.

Porter, M. and Kramer, M. (2011), "Creating shared value”, Harvard Business Review, No. Jan-Feb, pp. 62-77.

Priem, R.L. and Butler, J.E. (2001), "Tautology in the resource-based view and the implications of externally determined resource value: Further comments", Academy of Management Review.

Schmid, D. and Ritzrau, W. (2018), "Why the circular economy must link up the whole supply chain", Article is Part of the Sustainable Development Impact Summit.

Schnittfeld, N.L. and Busch, T. (2016), "Sustainability management within supply chains - A resource dependence view", Business Strategy and the Environment, Vol. 25 No. 5, pp. 337-354.

Snowden, D.J. and Boone, M.E. (2007), “A leader' s framework for decision making”, Harvard Business Review.

Weick, K.E. (1995), Sensemaking in Organizations (Foundations for Organizational Science), Sage Publications, London. 


\section{ACKNOWLEDGMENTS}

This article is one of the outcomes of the research project CIRCit (Circular Economy Integration in the Nordic Industry for Enhanced Sustainability and Competitiveness), which is part of the Nordic Green Growth Research and Innovation Programme (grant numbers: 83144) and funded by NordForsk, Nordic Energy Research, and Nordic Innovation. 